\title{
Challenges Faced by Women Entrepreneurs in Pakistan: A Qualitative Study
}

\author{
Ahmad Nawaz ${ }^{1, *}$ \\ ${ }^{1}$ Business School, University of Central Punjab, Lahore, Pakistan \\ *Correspondence: Business School, University of Central Punjab, Lahore, Pakistan. E-mail: \\ ahmad.nawaz1992@ucp.edu.pk
}

Received: March 26, $2018 \quad$ Accepted: April 11, $2018 \quad$ Online Published: April 17, 2018

doi:10.5430/mos.v5n2p13 URL: https://doi.org/10.5430/mos.v5n2p13

\begin{abstract}
Although there are big numbers of women entrepreneurs in Pakistan, and their percentage in the population is almost half $49.6 \%$. They can play an important role in the economy. In Pakistan, most of the studies were on opportunities for the women in Pakistan. In this study, we tried to explore research questions: what sort of difficulties are experienced by females "entrepreneurs" in Pakistan? How "societal and cultural aspects effect "women entrepreneurs" in Pakistan? For this purpose, I opted the qualitative research strategy. There were some emerging themes. In the end, I concluded this study, discussed some limitations, and suggested future directions.
\end{abstract}

Keywords: issues for entrepreneurs, women entrepreneurs, entrepreneurship, Pakistan, qualitative study

\section{Introduction}

The concept of Entrepreneurship has very long history, but the term 'Entrepreneur' was recognized in 1800s. With the progression of time and regular advancements of the idea of 'entrepreneurship', numerous writers and researchers have put their efforts on this unique notion. For example, traditional definition is "taking the risk of buying something on certain prices and then selling at uncertain prices" (Schumpeter, 2000). Ahmad and Symour (2008) argued that modern meanings (of entrepreneurship) have also encompassed the concepts of "innovation and disruption" to describe entrepreneurship.

Research on this context began in the mid of 1800 s, but it was associated as "male skill", while the females' role in entrepreneurship was hardly under consideration until the 1970s (Pines \& Schwartz, 2008). Richard Cantillon (1680 - 1734) was first writer who acknowledged the part of entrepreneurship, he noted "Entrepreneur is one who is involved in exchanges for profit and take critical decisions due to uncertainty in present, to sell again at indefinite price in future, with deference being their profits and loss" (Cantillon, 1979 - First edition, 1755). Moreover, another scholar contended that entrepreneurs show a central part for the growth of any particular economy of the country (Louw et al., 2003) and have their significant part in the development at national level (Hild, King \& Foster, 2005). In the countries of sub-continent (Bangladesh, India and Pakistan), development of entrepreneurship is presently a vital subject associated with economic progress in the countries. According to the economic growth theory in entrepreneurship stated that a country can increase its economic growth by increasing entrepreneurial activities.

There are a few researchers who kept up the investigation on female entrepreneurs who experience various restrictions. These incorporate an empirical consideration from one perspective (Gatewood et al., 2003), a deficiency of hypothetical establishment (Bush, 1992), the inattention of "structural, historical and cultural factors" (Chell \& Baines, 1998; Nutck, 1996), the utilization of measurement standards as for men (Moore, 1990; Stevenson, 1990) the "absence of a power point of view" and the nonappearance of "Feminist" investigation (Reed, 1996; Mirchandani, 1999; Ogbor, 2000).

Current studies display that these days, "women entrepreneurs" have gained much consideration by Media and academia for being a major player in the economy of a country (Carter \& Shaw, 2006). Furthermore, today women entrepreneurs play their role as backbone to the economy. The risk-taking (Entrepreneurial) activities vary across the region and culture. According to the Bruin, Bush and Welter (2006) the percentage of women entrepreneurship in 
developed countries is higher than in developing countries. Furthermore, culture plays a vital role whether country is developed or underdeveloped, for instance, Kingdom of Saudi Arabia has very restricted culture for women for different activities, more specifically for entrepreneurial activities. Regardless of the fact of evolution in women entrepreneurial activity globally, the ratio of women entrepreneurs is still less as to their opposite gender.

Previous investigations showed that women entrepreneurs experience difficulties and opportunities differently. According to the past content on this context, women entrepreneurs confront gender-related difficulties, such as not being acknowledged by society, e.g. in Saudi Arabia, Pakistan, etc.; 'lack of education' in societies where females unable to get education; social-cultural myth of being a housewife than as a 'breadwinner' of the household, as suggested by resource-based theory. They also confront common (Related to their opposite gender) challenges including capital arrangements, which are intensified because financial institutions hesitate in advancing credit to (Women) them. The hurdles faced by women entrepreneurs differ from culture to culture and county to country.

Even though abundant studies have been conducted on the context of women entrepreneurship worldwide, but there is lack of such study in Pakistan. There are limited studies that study the experience of precisely women entrepreneurs in Pakistan. This study's intention is to cover up that research gap via Qualitative Research strategy to get insights of this notion.

To get answers the following research questions are our study's core purpose: 1) what sort of difficulties are experienced by females "entrepreneurs" in Pakistan? 2) How 'societal and cultural aspects effect "women entrepreneurs" in Pakistan?

\section{Literature Review}

\subsection{Entrepreneurship}

The idea of Entrepreneur emerges with the history of mankind. In spite of the fact that, the name business visionary (Entrepreneurship), acquired from the French language, was first utilized as a part of the mid-eighteenth century, the idea of business and exchange has existed sometime before that. Risk-taking people (Entrepreneurs), who obtained products from one place and sold them in alternate place for monetary benefits were without a doubt entrepreneur of their time as they identify new open doors and went for risk to transform them into rewarding businesses (Dees, 1998).

Herron and Robinson (1993) stated that Smith (Economist) and Cantillon started examining "Entrepreneurship" in the mid-eighteenth century. From that point forward, numbers of studies have been completed regarding the context and different definitions or explanations have developed in the context of "entrepreneur" and "Entrepreneurship". Beginning scholars characterized it as "taking the risk of buying something on certain prices and then selling at uncertain prices". Advanced meanings of "Entrepreneurship" incorporated the idea of uniting elements of making something new. Ahmad and Symour (2008) argued that modern meanings (of entrepreneurship) have also encompassed the concepts of "innovation and disruption" to describe entrepreneurship. As indicated by Venkataraman's (1997) study, "Entrepreneurship is the connection of two phenomena: an ambitious individual and a rewarding open door." In accordance with his examination, another scholar characterizes "entrepreneurship" as "a procedure of finding, assessing and exploiting the open doors, which bring about presenting diverse products and services" (Shane, 2003). We argue that changing the routes in which markets, procedures, and crude materials are sorted out. He additionally characterizes it as building up another business or a non-government association which never existed.

"Entrepreneurship" has couples of conditions. 1) There ought to be an open door, which individuals figure they can catch and consolidate resources to pick up the advantage. 2) The distinctions in individuals are basic for entrepreneurship. In the event that there are no distinctions among individuals, everybody would perceive similar open doors and endeavor to underwrite them, making it hard for every other person to pick up advantage out of that open door. 3) There is always risk factor appended in catching an open door. 4) Entrepreneurship requires a type of innovation. Shane (2003) argued that it doesn't imply that the entire procedure ought to be innovative, it just requires a little development.

"Entrepreneurship" may similarly be characterized as a procedure of making an incentive through using time, putting energy and going out for monetary risk, which brings positive results in the term of Financial and social rewards. While commonly the reward of entrepreneurship is monetary, currently, it is non-money related also, for example, individual fulfillment and freedom (Hisrich, Peters and Shepherd, 2007). 


\subsection{Women Entrepreneurship}

"Entrepreneurship" is considered as an effective instrument to make job opportunities in any particular country, and female entrepreneur assumes a vital part in any nation. According to the economic growth theory in entrepreneurship stated that a country can increase its economic growth by increasing entrepreneurial activities. Recently, "female entrepreneurship" gained expansion in research. This imitates an expansion in "female entrepreneurs" globally. In spite of the developing numbers of female entrepreneurs (Boyd, 2005), Weller and Bernasek' (2001) study suggested that female's entrepreneurship capability is quite recently starting to emerge. In a report published by GEM (Global Entrepreneurship Monitor), in different 43 countries, the proportion of female entrepreneurship was lower as compared to their opposite gender (Malach-Pines and Schwartz, 2008).

On this context, another scholar argued that today the greater part of the organizations is claimed and controlled by men, in any case, the government in numerous nations is attempting to urge females to begin their own business (McGowan et al., 2012). The government organizations are giving encouragements to female business start-ups to take an activity towards "entrepreneurship". Insights demonstrate that the quantity of female claimed firms is expanding. As Wilson, Marlino and Kickul (2004) stated that there are currently over 6 million firms in different industries that are possessed by females in the United States of America.

These days, a bigger number of females are picking entrepreneurial ventures other than customary financial exercises that have been ascribed to females, for example, form outline and magnificence parlors. Presently female can be found in each segment even in those which were exceptionally male-dominated before. Studies conducted by "National Foundation for Women Business Owners (NFWBO)" uncovered that female entrepreneurship is a developing pattern comprehensively. Female entrepreneurship is influencing massive commitment to the economy, for example, the "Body shop", a worldwide business of beauty care products is claimed by Anita Roddick, a female business owner with a yearly generate over $\mathbf{\$ 1 . 2}$ billion in sales. In the USA, females claimed organizations have given over 12 million occupations which is higher than the employment made by the Fortune 500 organizations.

Thomas and Coughlin (2002) said that in USA 38 Percent of the organizations are claimed by females. For females, the thought process behind turning into a business visionary perhaps the same as males have. Females simply corresponding to their male partners may have a want for autonomy and monetary benefits (Davis \& Long, 1999). McGown et al., (2012) suggested that females additionally progress toward becoming the business person to help their families and to make a harmony between their workplace and household duties. An investigation that concentrated on why females move from employment to beginning their own business uncovered that there were a few explanations for it, some of which are freedom, superior opportunities, to work for themselves, adaptability of time and for getting more financial benefits (Bennett \& Dann, 2000). Hisrish and Brush (1992) distinguished some different elements for why females move to the enterprise are that they discover their activities not being valued and absence of acknowledgment at workplace prompting disappointment.

The ratio of female entrepreneurship is marginally not as much as men around the world. Global Entrepreneurship Monitor (GEM) is a central body that measures the entrepreneurial movements around the world. The gender gap shifts from location to location. There are nations where both genders (Male and female) have the same ratio in businesses, for example, Singapore, Thailand, Jamaica, Panama, Switzerland, Guatemala, Venezuela and Brazil (GEM Report, 2012). Shockingly, the nation who has the more numbers of female entrepreneurs than opposite gender is Ghana. As GEM's (2010) publishing showed that in Ghana, there is 55 percent of females who are engaged in the entrepreneurial activities (GEM, 2010). As per the report of GEM, there is a higher number of females who are holding the businesses in South American countries and Caribbean countries. Contradictory to this, Countries in the Middle East and South Asia have very low numbers of female entrepreneurs. Whereas Vossenberg, (2013) stated that Pakistan and Iran have a below normal female entrepreneurs' ratio in the world.

Tambunan (2017) argued, "The rate of women as the employer has not changed over the past ten years in Pakistan. However, the number of self-employed women has increased during the same time period. Women in Pakistan are mostly seen in self-employed units, much like the other countries of the region".

\subsection{Societal and Cultural Influence on Entrepreneurship}

The cultural and societal condition indicates to the intangible components including societal system and culture has a significant influence on people's living style, perception is also developed and influenced by the culture. Social and cultural setting play a dramatic part in changing and developing individuals' personalities. "Beliefs, values, habits and social conditioning" are the major components of the social and cultural 
atmosphere. Religion has its own importance in the society and culture to affect the individual's pattern of life. As Sumi and Akhter (2014) noted that cultural and social values were created over hundreds of years ago and are being shifted from generation to generation.

The social and cultural condition discharges the effects, both negative and positive, in the context of entrepreneurship. Thornton, Soriano, and Urbano (2011) recommended that these components may influence the development actions and performance of business people (entrepreneurs). Researchers clarify that entrepreneurship has not only monetary benefits but has Social benefits. Thus, "entrepreneurship is not just affected by the economic conditions of the environment but also the social and cultural aspects of the place where the entrepreneurial activity is being conducted" (Steyaert, 2007). Every nation has diverse physical conditions in view of the regular enrichment of things. In this way, the general population is living there need to adjust their practices equally to be fruitful. On this argument, the study conducted by Shapero and Sokol (1982) argue that the standards and values developed by the society have great influence on the choice of people to set up the new business.

Social and cultural components impact the entrepreneurial exercises from multiple points of view and it might shift geographically and culturally. There are basically two sorts of organizations that have an effect on the context of entrepreneurship, proper organization, government and informal institutions, for example, standards and the states of mind of the general public. The formal organizations may put confinements on some sort of business, yet may also give pushes to energize another sort of business. The standards and the nature of the general public affect entrepreneurial exercises particularly those performed by females. The guidelines of the game made by the general public can confine the entrepreneurial movement of females. It for the most part limits females to homebound exercises. Uzbekistan as an example, although the government of the country is facilitating and motivating females to enlisting their business social standards are putting pressure on entrepreneurship. In the same country, young girls who are living on the rural side of the country are supposed to do work at home before marriage. That's why, these young females who have the potential in business and have to earn some financial benefits but unable to get exposure, are gaining the financial benefits by taking conventional art business as they can do from home (Welter, 2011).

In the countries of the South Asian region, female entrepreneurs are more influenced by the social and cultural elements. In this region, there are many circumstances where females are unable to relish the flexibility of taking decisions and execute the monetary exercises. They are long ways behind men in these nations. There are numerous independent companies possessed by females in Bangladesh, which are not listed so they are not apparent in the economy of the country. The core issue with these females' actions is they do not have the fundamental information and help from the society. Females in Nepal showed they confront the threat of inappropriate behavior, the danger of individual's security and other difficulties, for example, not getting access to the required resources. In this area, a large portion of the females moves towards becoming business visionary due to pushing and supporting factors, for example, supporting the family, "poverty or emergency needs" (Tambunan 2009).

Females in the United Arab Emirates still confront problems because of their "strict culture" and specific standards. Religious and cultural rituals strongly affect society of UAE. Some preservationist part of the society still dislikes female business activists. The strong values of culture have demoralized females with the potential to take part in entrepreneurial exercises and requests them to remain in houses and take part in families' related activities. Females showed that their family or spouse is not helping them for business action. Along these lines, females in the UAE like to work out in the government sector (Goby and Erogul, 2011).

As Goheer's (2003) study show, "In Pakistan being in an atomic family improves the probability of females turning into a business visionary since females in atomic families have less association with the more previous generation and in this way, are less obliged by the social/cultural impact".

Religion similarly has its effect on entrepreneurial exercise. As an illustration, in Islam, bank advances on which you need to pay premium is denied and debilitated, consequently, it prevents to get access to borrowing from such bodies. Addition to this, Islamic banking may have a few answers for these issues yet despite everything it psychologically affects individuals. In the meantime, betting and liquor are denied in Islam, these are among the numerous different things that vacationers appreciate. It additionally restricts the entrepreneurial open doors for individuals, but, it isn't a gender-related issue (Akhter \& Sumi, 2014).

\subsection{Support and Challenges Faced by Female Entrepreneurship}

Female entrepreneurship confronts gender-related and also neutral difficulties. The social and cultural status of 
females, as indicated by which the essential part of females is taking care of residential duties, is one of the greatest difficulties females confront while beginning a business in the majority of the western nations (Bruni, Gherardi and Poggio, 2004). Additionally, they claim that the majority of the female business visionary's confronted problem during the arrangement of capital for their business. Financial Organizations such as banks, companions and even relatives dither or refuse to help females monetarily, in light of the fact that they expect that "females can't deal with cash." Klapper and Parker (2010) bring up that in underdeveloped nations, for example, Uganda, Pakistan, Kenya, India and Bangladesh funding for business is a genuine difficulty for females. For new startups and development of the business, it is a difficult bridge to cross over.

In Asian regions and African regions, females utilize their reserve funds or depend on informal funding which is costly, in light of the fact that formal funding choices are less accessible to females. According to the Resource-based theory, "individuals leverage different types of resources to get entrepreneurial efforts off the ground. Access to capital improves the chances of getting a new venture off the ground, but entrepreneurs often start ventures with little ready capital. Other types of resources entrepreneurs might leverage include social networks and the information they provide, as well as human resources, such as education. In some cases, the intangible elements of leadership the entrepreneur adds to the mix operate as a resource that a business cannot replace." Keeping in mind the end goal to get a credit from financial institutions females, for the most part, confront issues. They don't have a solid record of loan repayment or they don't have a decent security to give. The issue with the record as a consumer is that a large portion of the bills, credits and utilities are for the sake of their father or spouse (Parker \& Klapper, 2010).

Females in Kenya stated during the study in this context that they feel segregated. When they (Females) approach to the banks for the obtaining the funds with their spouse, they are being overlooked and the bank authorities are simply cooperating just with their male accomplices. As Mwobobia (2012) said that in Kenya, females have a discernment about the banks that they are one-sided, so they withdraw from moving toward the banks and attempt to get sponsoring from other sources. Roomi and Parrott (2008) discovered that females in Pakistan confronted gender unbiased issues, most essential of which was the absence of assets in the development stage, due to this female possessed organizations are normally little scale.

Bruni, Gherardi, and Poggio (2004) discovered that "females have restricted or feeble access to data and contacts which is because of their restricted social circle". McIntosh, J.C., and Islam, S. (2010) recommends that "entrepreneurs who have encouragement from their family have better access to business systems. In many immature and emerging nations, females similarly have lack of experience and the appropriate training that is important to begin and work a business, (Klapper \& Parker, 2010). For example, in Kenya, Poor level of training has put females at weakness when contrasted with men". Despite the fact that "there has been a decline in the gender gap in the elementary school but regardless it stays in secondary schools. Along these lines, females unable to get the training and information important to begin and maintain a business" (Mwobobia, 2012).

A study conducted by FSB (Federation of small business, 2016) discovered that "unlike men, women feel that they lack the skills to start a business and they are more afraid of being failed. $22 \%$ of the females in this study showed that lack of self-confidence was one of the major challenges they faced when starting the business". Shinnar, Giacomin, and Janssen (2012) did an investigation in three nations China, Belgium, and the United States and found that "in every one of these nations three restrictions were common which were the anxiety of disappointment, the absence of competency and absence of help. Females saw these blocks more imperative than men in these three different nations".

Another latest study suggested that family encouragement is truly critical for female entrepreneurship. On the off chance that the family is strong, it might have a positive effect on the development of the business and if the family isn't helpful it will negatively affect the female business person. For a fruitful female business, visionary help is the key component. McClelland et al., (2005) found that "Protection from the family is another significant issue for female business people in numerous nations". This boundary is for the most part regular in underdeveloped nations where there are solid family backgrounds. In underdeveloped nations females' essential part is to deal with the family and perform assignments that are family related.

In Pakistan, female entrepreneurship does not obtain the value and opportunities as compared to their opposite gender due to the great influence of society and culture norms and standards profoundly established. In the man dominant society like Pakistan, the issues were intensified for the females. "Pardha (Veil), spatial immobility and lack of institutions offering technical skills to females were issues confront by female entrepreneurs in Pakistan" (Roomi \& Parrott, 2008). They added more, a great number of men were against the taking guidelines or 
working under female supervisor due to cultural aspects.

The issues are most apparent in the help instrument accessible to help female entrepreneurs in Pakistan. Females need access to "investment, land resource, technological information and other critical assets", which brings about underutilization of their potential. Pakistan being a male-centric culture holds the intrinsic state of mind that females are second rate compared to men and that they are most appropriate to be housewives. This state of mind makes huge difficulties and issues for female entrepreneurs. Inside their own family, the majority of the situations females get little empower from the male individuals, diminishing their capacity to move all over the place (Roomi \& Parrott, 2008).

The administration of Pakistan additionally found a way to advance female business entrepreneurship. Micro Financial institutions were acquainted in the nation with the development of female entrepreneurship, however, the issue was that the females needed entrepreneurial abilities and training (Mahmood, 2011). As indicated by Goheer (2003) "the Article 25 of the Constitution of Pakistan (1973) ensures equity of rights to all residents independent of gender, race, and class and furthermore enables the legislature to make a move to secure and advance females' 123 rights". Syed (2010) recommends that "the service of females' improvement in Pakistan as a team with United Nations Development Program is attempting to help and prepare females to engage them". The progression provisions were centered on females. Plans have been boosted to help females monetarily. Financial Institutions, for example, "First Women Bank Limited, Pakistan Poverty Alleviation Funds and the SME Bank" are engaged with pushing such plans. The "Women Chamber of Commerce and Industry" is an imperative organization which reflects females in the business.

By the literature, it can be presumed that females globally confront gender-related and unbiased issues. Female's business visions are influenced by social and cultural variables. In the advanced nations, this context has accomplished its consideration and a great deal of research is being done on it however in underdeveloped nations, for example, in Pakistan, there is a deficiency of research, that's why this subject was chosen for investigating in Pakistan. The above writing was utilized for exploration of queries.

\section{Methodology}

This chapter of our research describes the methods used for data collection it also defines the sample size and population used for collecting data.

\subsection{Research Strategy}

The research questions we used for this study were exploratory in nature. This paper has the aim of getting insights of the phenomena of experience or challenges faced by women entrepreneurs in Pakistan. There are few researchers who have worked in the field of entrepreneurship in Pakistan, similarly, the context of women entrepreneurship is unable to get attention for the study, especially in Pakistan. Therefore, this research paper discovers the issues which have not been discussed before in Pakistani context. To get a detailed understanding of why women want to become entrepreneurs and what are the social and cultural effects we conducted open-ended interviews

The research method that we chose to use was qualitative research to get detail and in-depth information by interviews because we want to explore the insights of the issue.

As Bryman and Bell (2011) suggested that quantitative method produce numerical data, on the other hand, qualitative research method caters to explanatory data. On qualitative research method, Neergaard and Ulhoi (2006) argue that qualitative research method is more suitable to understand the phenomenon of the entrepreneurship because it gives the in-depth analysis of the phenomenon and is more detailed based. Bryman and Bell (2011) revealed their distress over the subjectivity of the qualitative research method they said that in qualitative research the researcher might interpret the behaviors of the participants which can lead to unreliable results.

\subsection{Research Method}

We used semi-structured interviews to get the original point of views or responses while collecting data for this research. Quinlan (2010) stated that this method helps the researcher explore the views and thoughts of the respondent's in the same context. This method is more like to normal conversation. For this research, this data collection technique seemed to be best as respondents open up and share their experiences in detail, challenges. Although, this technique is highly time-consuming, but gives a lot of useful data. 


\subsection{Data Analysis}

As we have to analyze the opinions and thoughts of the respondents all the interviews conducted were recorded on a device so none of the important information is missed. We transcribed the interviews, although this process is very time taking it was very important to get productive data.

Analyzing the data in qualitative research follow few steps, first is to transcribe the interviews and then organize them and categories them into meaningful themes and subthemes. In literature, this step is known as "Coding" (Lapan \& Riemer, 2013). Similarly, Delahaya and Sekaran (2001) recommended that during analyzing the data, coding is essential in qualitative research. We developed themes and subthemes, then we explained them in the finding chapter.

\subsection{Sampling Design and Sampling Size}

In qualitative research strategy, it is very difficult to organize the large data, because interviews are also time taking, therefore we developed sampling. We used snowball sampling. In snowball sampling, the writer or researcher finds some relevant respondents to his/her study and then these participants refer another participant (s) (Quinlan, 2011). On the other hand, this sampling method has some drawbacks as suggested by Bryman and Bell (2011), first, it can lead to biased results because people mostly refer those people who have similar attributes due to the social connection (Sadler et al., 2010).

While keeping in mind that there is limited time for this study, we planned to conduct ten interviews. Based on this research paper, our all respondents were women who were engaged in entrepreneurial activities. In our sample size, we had some entrepreneurs with experience more than five years, and few had less than five years. All interviews were conducted through telephones due to their busy schedules, and all respondents were based in Lahore. The participants are from different business sectors such as textile fashion industry, Marketing Industry, Event Management, Trading, and Crafting.

\section{Analysis and Findings}

In this chapter, we have interpreted the discoveries based on the responses of our sample (Women Entrepreneurs from Pakistan) and we scrutinized our data very carefully. For interpretation, we divided this chapter into two sub-chapter, and we did on the grounds of our two research questions. In the first sub-chapter, we have discussed the challenges or experiences confronted by women entrepreneurs, in the second sub-chapter we discussed the effect of culture and social dynamics or aspects on women entrepreneurs.

\subsection{Experiences Confronted by Women Entrepreneurs}

As we have mentioned in methodology chapter, we conducted ten interviews from different women who were engaged in entrepreneurial activities of Pakistan, and these women had different years of experience, and were involved in diverse industries showed attention-grabbing outcomes. After analyzing the data we came upon this argument that most of the respondents encountered experiences related to each other, but there were new emerging challenges or experiences we obtained during the data analysis based on our data.

\subsection{Funding}

For any kind of startup, funds or capital is an essential component, to handle expenses including fixed expenses (Building, utility bills etc.) and variable expenses (Wages, Inventory, etc.). Based on our data, almost all respondents had parallel answers on funding or capital. And the high frequency of respondents shared that for the initial investment their families supported them, in later stages they used they're retain earning to expand their startups. After critically analyzing the data, we argue that women entrepreneurs encountered the financial barrier for their initial investment. They also shared that there is a limited source of capital in the financial markets, therefore they asked their families, an interviewee shared:

"We did not have any idea about how the business would come along, therefore, we found it appropriate to pool in our savings for the initial advertisement. However, the majority of the work was done by us and both our families were a great support. Some investment was theirs too." (School Owner)

Similarly, another interviewee shared that the biggest issue I encountered was related to capital or getting finances for the startup, she shared:

"When I thought of starting my business I had no idea about the finance so I asked my friend who 
first agreed to invest in my business as a partner but at the eleventh hour he refused to invest which put me in shock and trouble. My venture was delayed for this reason. Later I found another friend who joined me as my business Partner. We used his money and my savings, I also had to borrow some money from my mom which I felt really awkward so I returned her after sometime." (Designer)

To strengthen our argument a professional photographer (interviewee) shared her story or experience regarding financing difficulties and this challenge cause the slow growth of her business, she said:

"If my family had given me the amount of money I was asking, today I would have been in a much better position. Finance has been a huge hindrance in my growth. In my business, to grow, I have to buy better equipment which I buy from my profits..."

In the literature, Burni, Gherardi and Poggio (2004) suggested that families are core source for obtaining the initial investment and entrepreneurs faced this as biggest challenging, this challenge also cause for slow growth in the business.

In our data set, they had a small-scale business, seven out of ten had small businesses. According to Tur-Porcar and Beslo (2016) businesses owned by women are in the small business category, and the biggest challenge they face is related to arrangements of capital, as our data showed as well. A larger proportion of our dataset shared that the core cause for slowing the growth rate was inaccessibility to capital resources.

During the study, religious point of view has emerged. One of our respondents shared that she approached the bank for financing, in the banks or other financial institutions charge interest on that amount for particular time, and Interest is strictly outlawed in Islam as mentioned in the Holy Book. Without access to capital, depending entirely on the support of relatives and family, the growth of her business is not good as it must be.

\subsection{Social Acceptance}

Society plays an important role in our external activities, as in Pakistan society has its great influence on both gender, but for women especially for businesswomen has social pressure. Our data showed important outcomes, data showed that there is a social acceptance as a barrier encounter by women in Pakistan while starting their own business. An owner of the beauty institute shared:

"When I started my business in 1980, I went door to door in the neighborhood introducing my salon. At that time it was hard in the beginning. While I was introducing my parlor in the neighborhood one of the ladies shut her door when I told her that I'm your neighbor and I'm starting a beauty parlor. She said 'women like you spread filth in our society' I was shocked and couldn't understand whether it was for my profession or being a single parent.",

But nowadays, women entrepreneurs emerged as an important factor for the growth of national economy. So, society has changed its point of view as compared to in 1980's. A market firm's owner started her business in 1997, she shared her story on this theme as:

"We couldn't win projects at the beginning of our career just because people thought we were females they didn't take us seriously. Later we showed them we are capable of everything. Now after years of experience, I don't think people are biased towards us."

The similar respondent commented that situations have been transformed now, in Pakistan women are being respected for their entrepreneurial activities. On the grounds of our research, society showed the resistance for women for being businesswomen thirty years ago. Two years ago one of our respondents started her new venture and she shared that people out there were supportive and she did not encounter any resistance as much. Moreover, she commented that she felt that society was there for the support because in Pakistan situation has been changed towards women who are engaged in business activities, and this not cultural shock anymore. The rate of women entrepreneurs has been increased from last two decades.

\subsection{Convincing Family}

In our data set, they showed that they had to convince their families to pursue the entrepreneurial activities in Pakistan, based on our this result we argue that Pakistan's societal norms have significant influence while pursuing the entrepreneurial activities across the gender but it is more difficult for the females. A real-time case we mentioned here to support our argument, a young engineer, currently working in the well-reputed company of Pakistan, he wanted to pursue his own business of "Goat Farming" but due to the pressure or influenced by his family, he had to drop this idea and continue to his current job. We suggest that this issue is not only related to females but males also 
face this barrier.

But in Pakistan females have to get permission before they get involved in any entrepreneurial exercise, but on the other hand when we see females in other countries such as USA, Australia, etc. they (Females) don't have to get any kind of permission to pursue an entrepreneurial activity.

One of our respondents shared her view or experience on this challenge as she faced while pursuing her own business:

"Actually my parents didn't want me to work. They wanted me to get married after completing my studies. It was really hard for me to convince my parents to allow me to work. My degree was in accounting and finance but photography was my passion. They also had a problem with my choice of business. They thought if I wanted to work, do something related to your studies."

On this challenge, another respondent shared her story on the similar obstacle she faced that her parents did not like her business, she owns a business of Academia/ counseling:

"...It was very hard initially to get parents to agree that it is okay for their children to be anything other than a doctor or an engineer and that all career choices are equally respectable... It is hard to break rigid mindsets especially when it becomes a norm and when you are interacting with people who are old enough to be less flexible when it comes to mindset."

As our respondents indicated that although it was difficult of them to convince their families to pursue their businesses but after they were able to convince them, they got a very strong support by their families. Above theme "Finance" discussion do support our argument on this issue. In the prior studies, Tur-Porcar and Belso (2016) argued that there would be positive impact on the business when families are supportive and there would be negative impact on business when families are unsupportive. In addition to this, McIntosh, J.C. and Islam, S. (2010) recommended that "entrepreneurs who have encouragement from their family have better access to business systems.

\subsection{Communication}

During interviews we asked regarding the communication issue with suppliers, four respondents stated that they faced issue of communication with their suppliers. They shared that there is myth or perception about women that they are weak but they stated that after working with them, they (Suppliers) recognize we are not weak. As an entrepreneur stated:

"In our society men perceive women as weak. So, yes I faced challenges communicating with them.

But I was strong and I proved everyone that what I'm capable of. Now people see me as a strong

lady. You have to change the perceptions of others by proving them wrong and making yourself strong." (Beauty Parlor Owner)

As we stated that four respondents confronted this issue but there are some cases where women did not face any communication challenge with their suppliers. They indicated that their suppliers are supportive and respectful. There are three respondents who have males as a business partner, therefore they do not have to take part this business activity. A female entrepreneur who is engaged in manufacturing business shared:

"I am in less contact with supplier and vendors because all local dealing is under the care of my brother (Partner) and yes while communicating with local there were some challenges in past but now with the passage of time people are more welcoming for females in business world"

\subsection{Work-Life Balance}

In the literature, females confront work-life balance challenge because they have great responsibilities at home. As we have discussed in the literature, they have to take care of their children and other family's responsibilities. Our respondents also indicated the related results. Some of our respondents shared that they are unable to get time for their families due to busy business activities. They stated that it was difficult for them to maintain a balance in the initial stage of the business. After the stable position of the business, maintaining the balance is possible. A marketing firm owner shared her story:

"In the beginning, you have to concentrate on the business so yes it does affect family life. Relationships are demanding but the other person should understand that work is not a joke and you are also not a joke. So, you have to balance it yourself..."

Our data showed that the issue of work-life balance is based on the nature of the business. For instance, it is easy to maintain the balance if the business is being operated from home such Crafts etc. A respondent who is engaged in 
beauty parlor business stated:

"As I started as a single parent. It did affect my family life. I have a son. Who was 3 when I started business, I couldn't give him proper time in the beginning because I was struggling for my business. But later I manage to create a balance between work and life."

In the light of our data, maintaining the work-life balance is affected by marital status. In our data set, there were six respondents who were single, five out of them stated that they couldn't find this issue at initial stages of business, still, they are not confronting this challenge. According to them being single leads them to concentrate more on business activities as they do not have such family-related responsibilities. In the literature, McClelland et al. (2005) suggested that for female entrepreneurs work-life balance problem has a great impact on the success of their business.

\subsection{Working with Extended Relatives}

Our respondents indicated an interesting finding. There are two respondents shared that they face challenges in their extended relations. They stated that their relatives do not give any value to their business. They assume that their business is of low quality or they asked for handsome discounts/offers. As professional photographer shared her experience:

“... Working with relatives has been a challenge for me. They get their work done and they expect me to charge the minimum and they usually don't pay and I cannot ask again and again. Now I have learned that not to work with relatives because they don't value your work."

We were unable to find out the relevant argument in the past studies, that's why this "Theme" is new which is indicated by our respondents. Therefore, this theme is attention-grabbing not only for this study but also for the future research on different countries to validate it.

\subsection{Moral Support}

As our respondents showed that women entrepreneur not only confronts financial or family support but they need moral support as well. Almost every single respondent who participated in this study stated that females need both financial and moral support. In addition to this, Janssen, Giacomin and Shinner (2012 suggested that sometimes they seek more moral support than financial support.

Respondents showed that they were lucky enough to have every kind of support they need while pursuing the venture (s). As one interviewee shared her experience, as she is engaged in Crafts and Event decor:

\section{"Demoralization from my family has been a very mundane case, who clearly stated my business would result in a complete failure..."}

\subsection{Impact of Social and Cultural Aspects on Women Entrepreneurs}

To address the second question of this study, women entrepreneurs were asked regarding the impact of social and cultural aspects on this context. Family support is one of the most important factors in the society for the women while pursuing the business activities. As we have discussed in question 1, most of the respondents stated that they need both moral support and financial support. Most of the respondents shared their experiences about their family support and some of them give all credits to their families for their success, an entrepreneur (Pharmaceutical Company) stated:

\section{"...without the support of my family, it was not possible for me to achieve what I have achieved today."}

In the prior studies, Tur-Porcar and Belso (2016) argued that there would be a positive impact on the business when families are supportive and there would be a negative impact on business when families are unsupportive. In addition to this, McIntosh, J.C. and Islam, S. (2010) recommend that "entrepreneurs who have encouragement from their family have better access to business systems. Peer groups have also a great influence on new ventures, especially for the women.

Norms in a particular society play an important role to boost or motivate the entrepreneurial activities. During interviews, respondents respond inversely when we asked them about societal norms. Based on our data set, we can conclude that norms developed by the society have great influence on the entrepreneurial activities. For example, Kingdom of Saudi Arabia has a very restricted culture for women for different activities, more specifically for entrepreneurial activities. The traditional contribution of women was restricted. Activities were related to just home. Our study suggests that the passion for doing something was their inspiration, the owner of crafts and event organizer 
stated:

"My passion and love for arts is my biggest inspiration. I always wanted to do something that doesn't make me feel as if I am working..."

In the light of above arguments, we can say that the norms developed by the society in Pakistan have great influence for the women entrepreneurs. But now society is being changed for the last few years. Respondents revealed that education is the most important factor in the society. Addition to this, a scholar commented that "Lack of education" push women back or restrict them. One of the respondents stated:

\section{"...Education has played a huge role in cutting out defined gender roles."}

Based on results we can argue that education is an important aspect which has a positive impact on entrepreneurial activities.

Religion has also a great influence, as it shows the guidelines for the people. According to our data, Islam permits women to take part in business activities. An entrepreneur (Owner of Pharmaceutical Company) stated:

“...my norms and values are based on my religion which is Islam and the very first wife of our prophet was a businesswoman, named as Khadijah."

An owner of a Manufacturing company stated:

“...on top of everything our religion Islam allowed women can do business as Hazrat Khadijah (AS) did in the history of Islam."

Religion has its own importance in the society and culture to affect the individual's pattern of life (Akhter \& Sumi, 2014).

\section{Conclusion}

In this chapter, we concluded the study, we discussed the limitations and proposed some future direction for the future study in this context. The purpose of this study was to explore the issues or experiences confronted by Pakistani Women entrepreneurs and influence of social and cultural aspects of women in Pakistan to pursue their own business.

In the light of outcomes, we argued that still there are some barriers experiencing or confronting by women in Pakistan, but with the passage of time these have been reduced. There are seven different themes which were emerged, some themes were new and we could not find any relevant literature. In Pakistan, women confront the barrier such as financial, support from the family were recognized during analysis, but time has changed, nowadays, families are more supportive than a few years back.

Another experience they confront is acceptance by the society. On the other hand, respondents shared that over the last few years society has advanced and support women for these business activities. This study also recognized working with extended family, family support, communication and convincing families as problems confronted by women in Pakistan.

The attention-grabbing outcome was females in Pakistan asked their families for the capital support than asking from the government. Societal norms have been changed, nowadays people do support female to start their new venture and emerge as powerful contributors to the society and economy of Pakistan. Education plays an important role in the changing the mindsets of the society, from last few years Pakistan is improving the educational sector, which helps to break the myth that women are responsible for home-related work. In the last, Islam also supports women in these activities.

\subsection{Limitations}

The first and important limitation of this study is it is based on only nine respondents because qualitative research consumes the time, by this, we cannot generalize the outcomes. Almost all interviews were conducted through phone, we were unable to note their body language. Snowball sampling technique has its own limitations, in this, people refer to those people who have almost same attributes. That's why in this, not any single respondents stated that government initiatives to boost women entrepreneurs in Pakistan, may be due to snowball sampling.

\subsection{Further Research}

Although this study tried to capture all aspects of the context but still there is need to get more investigation, due to time constraint we were limited to conduct ten interviews, therefore, there is need to increase the sample size, and it 
should be from different cities of Pakistan, because maybe there are different situations geographically. By using triangulation technique, the knowledge on this context can be enhanced. Nowadays, trans-genders are taking part in such entrepreneurial activities and changing their traditional profession, there is clear research direction to investigate the entrepreneurial opportunities for them in Pakistan.

\section{References}

Achtenhagen, L., \& Welter, F. (2011). 'Surfing on the ironing board'-the representation of women's entrepreneurship in German newspapers. Entrepreneurship \& Regional Development, 23(9-10), 763-786. https://doi.org/10.1080/08985626.2010.520338

Ahmad, N., \& Seymour, R. G. (2008). Defining entrepreneurial activity: Definitions supporting frameworks for data collection.

Akhter, R., \& Sumi, F. R. (2014). Socio-cultural factors influencing entrepreneurial activities: A study on Bangladesh. IOSR Journal of Business and Management, 16(9), 01-10. https://doi.org/10.9790/487X-16920110

Bennett, R., \& Dann, S. (2000). The changing experience of Australian female entrepreneurs. Gender, work \& organization, 7(2), 75-83. https://doi.org/10.1111/1468-0432.00095

Boyd, R. L. (2005). Race, gender, and survivalist entrepreneurship in large northern cities during the Great Depression. The Journal of Socio-Economics, 34(3), 331-339. https://doi.org/10.1016/j.socec.2004.09.018

Bruni, A., Gherardi, S., \& Poggio, B. (2004). Entrepreneur-mentality, gender and the study of women entrepreneurs. Journal of Organizational Change Management, 17(3), 256-268. https://doi.org/10.1108/09534810410538315

Brush, C. G. (1992). Research on women business owners: Past trends, a new perspective and future directions. Entrepreneurship: Theory and Practice, 16(4), 5-31. https://doi.org/10.1177/104225879201600401

Cantillon, R. (1979). Essaisur la nature du commerce in general, as quoted in Entrepreneurship in the Hospitality, Tourism and Leisure Industries.

Cardon, M. S., Zietsma, C., Saparito, P., Matherne, B. P., \& Davis, C. (2005). A tale of passion: New insights into entrepreneurship from a parenthood metaphor. Journal of Business Venturing, 20(1), 23-45. https://doi.org/10.1016/j.jbusvent.2004.01.002

Carter, S. L., \& Shaw, E. (2006). Women's business ownership: Recent research and policy developments.

Chell, E., \& Baines, S. (2000). Networking, entrepreneurship and microbusiness behavior. Entrepreneurship \& regional development, 12(3), 195-215. https://doi.org/10.1080/089856200413464

Coughlin, J. H., \& Thomas, A. R. (2002). The rise of women entrepreneurs: People, processes, and global trends. Greenwood Publishing Group.

Dees, J. G. (1998). The meaning of "social entrepreneurship". Retrieved from http://e145.stanford.edu/upload/articles/dees_SE.pdf

Gatewood, E. J., Carter, N. M., Brush, C. G., Greene, P. G., \& Hart, M. M. (Eds.). (2003). Women entrepreneurs, their ventures, and the venture capital industry: An annotated bibliography. Entrepreneurship and Small Business Research Institute (ESBRI).

Goby, V. P., \& Erogul, M. S. (2011, August). Female entrepreneurship in the United Arab Emirates: Legislative encouragements and cultural constraints. Women's Studies International Forum, 34(4), 329-334. https://doi.org/10.1016/j.wsif.2011.04.006

Goheer, N. A. (2003). Women entrepreneurs in Pakistan. International Labour Organization.

Herrington, M., Kew, J., \& Kew, P. (2010). Global entrepreneurship monitor. Retrieved March 28, 2015.

Herron, L., \& Robinson, R. B. (1993). A structural model of the effects of entrepreneurial characteristics on venture performance. Journal of Business Venturing, 8(3), 281-294. https://doi.org/10.1016/0883-9026(93)90032-Z

Hisrich, R. D., Peters, M. P., \& Shepherd, D. A. (2007). The Entrepreneurial Mindset.

Klapper, L. F., \& Parker, S. C. (2010). Gender and the business environment for new firm creation. The World Bank Research Observer, 26(2), 237-257. https://doi.org/10.1093/wbro/lkp032

Louw, L., Van Eeden, S. M., Bosch, J. K., \& Venter, D. J. L. (2003). Entrepreneurial traits of undergraduate students 
at selected South African tertiary institutions. International Journal of Entrepreneurial Behavior \& Research, 9(1), 5-26. https://doi.org/10.1108/13552550310461027

Malach-Pines, A., \& Schwartz, D. (2008). Now you see them, now you don't: gender differences in entrepreneurship. Journal of Managerial Psychology, 23(7), 811-832. https://doi.org/10.1108/02683940810896358

McClelland, E., Swail, J., Bell, J., \& Ibbotson, P. (2005). Following the pathway of female entrepreneurs: A six-country investigation. International journal of entrepreneurial behavior \& research, 11(2), 84-107. https://doi.org/10.1108/13552550510590527

McGowan, P., Redeker, C. L., Cooper, S. Y., \& Greenan, K. (2012). Female entrepreneurship and the management of business and domestic roles: Motivations, expectations and realities. Entrepreneurship \& Regional Development, 24(1-2), 53-72. https://doi.org/10.1080/08985626.2012.637351

Mirchandani, K. (1999). Feminist insight on gendered work: New directions in research on women and entrepreneurship. Gender, Work \& Organization, 6(4), 224-235. https://doi.org/10.1111/1468-0432.00085

Moore, D. P. (1990). An examination of present research on the female entrepreneur-Suggested research strategies for the 1990's. Journal of Business Ethics, 9(4), 275-281. https://doi.org/10.1007/BF00380327

Mwobobia, F. M. (2012). The challenges facing small-scale women entrepreneurs: A case of Kenya. International Journal of Business Administration, 3(2), 112. https://doi.org/10.5430/ijba.v3n2p112

Ogbor, J. O. (2000). Mythicizing and reification in entrepreneurial discourse: Ideology - critique of entrepreneurial studies. Journal of management studies, 37(5), 605-635. https://doi.org/10.1111/1467-6486.00196

Reed, L. R. (1999). Troubling boys and disturbing discourses on masculinity and schooling: a feminist exploration of current debates and interventions concerning boys in school. Gender and Education, 11(1), 93-110. https://doi.org/10.1080/09540259920780

Reimers-Hild, C. I., King, J. W., Foster, J. E., Fritz, S., Waller, S. S., \& Wheeler, D. W. (2005). A framework for the" entrepreneurial" learner of the 21st century. Faculty Publications: Agricultural Leadership, Education \& Communication Department, 33.

Roomi, M. A., \& Parrott, G. (2008). Barriers to development and progression of women entrepreneurs in Pakistan. The Journal of Entrepreneurship, 17(1), 59-72. https://doi.org/10.1177/097135570701700105

Schumpeter, J. A. (2000). Entrepreneurship as innovation. Entrepreneurship: The Social Science View, 51-75. Available at SSRN: https://ssrn.com/abstract $=1512266$

Shane, S. A. (2003). A general theory of entrepreneurship: The individual-opportunity nexus. Edward Elgar Publishing. https://doi.org/10.4337/9781781007990

Shapero, A., \& Sokol, L. (1982). The social dimensions of entrepreneurship. In C.Kent, D. Sexton and K. Vesper, (Eds.), Encyclopaedia of entrepreneurship, 72-90.

Shinnar, R. S., Giacomin, O., \& Janssen, F. (2012). Entrepreneurial perceptions and intentions: The role of gender and culture. Entrepreneurship Theory and practice, 36(3), 465-493. https://doi.org/10.1111/j.1540-6520.2012.00509.x

Stevenson, L. (1990). Some methodological problems associated with researching women entrepreneurs. Journal of Business Ethics, 9(4), 439-446. https://doi.org/10.1007/BF00380343

Steyaert, C. (2007). 'Entrepreneuring'as a conceptual attractor? A review of process theories in 20 years of entrepreneurship studies. Entrepreneurship and regional development, 19(6), 453-477. https://doi.org/10.1080/08985620701671759

Syed, J. (2010). Women and small business entrepreneurship in Pakistan. Edward Elgar.

Tambunan, T. (2009). Women entrepreneurship in Asian developing countries: Their development and main constraints. Journal of Development and Agricultural Economics, 1(2), 27-40.

Tambunan, T. T. (2017). MSMEs and Access to Financing in a Developing Economy. Financial Entrepreneurship for Economic Growth in Emerging Nations, 148.

Thornton, P. H., Ribeiro-Soriano, D., \& Urbano, D. (2011). Socio-cultural factors and entrepreneurial activity: An overview. International small business journal, 29(2), 105-118. https://doi.org/10.1177/0266242610391930

Venkataraman, S. (1997). The distinctive domain of entrepreneurship research. Advances in entrepreneurship, firm 
emergence and growth, 3(1), 119-138.

Vossenberg, S. (2013). Women Entrepreneurship Promotion in Developing Countries: What explains the gender gap in entrepreneurship and how to close it. Maastricht School of Management Working Paper Series, 8, 1-27.

Welter, F. (2011). Contextualizing entrepreneurship - conceptual challenges and ways forward. Entrepreneurship Theory and Practice, 35(1), 165-184. https://doi.org/10.1111/j.1540-6520.2010.00427.x

Wilson, F., Marlino, D., \& Kickul, J. (2004). Our entrepreneurial future: Examining the diverse attitudes and motivations of teens across gender and ethnic identity. Journal of Developmental Entrepreneurship, 9(3), 177.

Appendix - 1

$$
\text { Semi - Structured Interview Questionnaires }
$$

1. Please tell us about your Venture? Share your history.

a. What was your inspiration? (if require)

2. What were your initial steps for your business?

3. How did you arrange capital for the startup?

4. Did you use any formal source of funding?

5. Have you confronted any kind of issue during hiring people?

6. What source of communication do you use to make communication with your vendors? Are you facing any kind of challenge?

7. Being an entrepreneur, tell us about your work-life balance? What does your family think about you?

8. What were reactions of your social circle, such as friends etc.? Share shocking comments.

9. Based on your experience in the market, still, women require any kind of support while pursuing new venture?

10. Being an entrepreneur, does social and cultural norms relate to your culture (family Culture)?

11. According to you, what is the role of education in entrepreneurship?

12. What is your extreme fear concerning to your venture?

13. Have you faced any barrier in your practice? And what you have learned?

14. While pursuing the start-up, what do you think about men and women confront diverse problems in Pakistan?

15. Does Pakistan government initiate any kind supportive programs for the entrepreneurs? Is there a difference for both gender?

Appendix -2

Transcribed

Note: Transcribed can be shared on demand. 